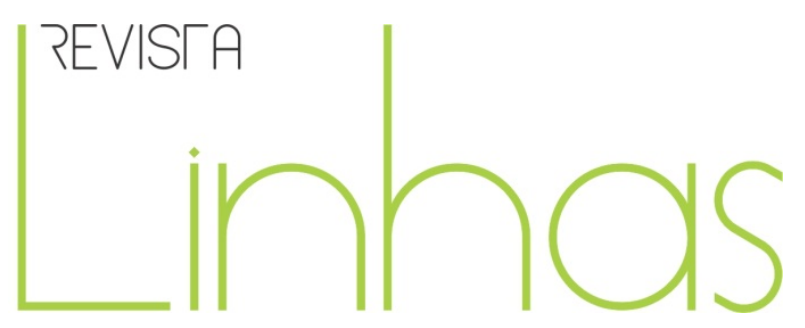

\title{
A contestação e a resistência da criança do Abrigo Provisório para Menores Abandonados de Santa Felicidade (Curitiba, 1947-1953)
}

\begin{abstract}
Resumo
O presente texto identifica e analisa a contestação e a resistência da criança, em situação de pobreza e abandono, que se encontrava no Abrigo Provisório para Menores Abandonados de Santa Felicidade, no período de 1947 a 1953, na cidade de Curitiba. Deste modo, aproxima-se de fragmentos de vida das crianças que nessa instituição construiriam parte de suas trajetórias de vida. A problemática da abordagem reside em inquirir a História e a Historiografia através da indagação: que mecanismos de contestação e resistência podem ser identificados nas atitudes das crianças em situação de pobreza e abandono frente aos encaminhamentos da instituição? A análise das fontes pela perspectiva da História Sociocultural permite considerar que o principal mecanismo de contestação por parte da criança se manifestava no ato de forjar sua própria identidade; e como principal mecanismo de resistência, a atitude de fugir da instituição. Diante da atitude de forjar sua própria identidade e fugir, geralmente levando outras crianças consigo, a criança emerge como sujeito de sua própria história.
\end{abstract}

Palavras-chave: Criança. Infância. Contestação. Resistência. Abrigo Provisório.

\section{Joseane de Fátima Machado da Silva}

Doutoranda em Educação pela Universidade Federal do Paraná, na Linha de História e Historiografia da Educação. josy_fm@hotmail.com

\section{Para citar este artigo:}

SILVA, Joseane de Fátima Machado. A contestação e a resistência da criança do Abrigo

Provisório para Menores Abandonados de Santa Felicidade (Curitiba, 1947-1953). Revista Linhas,

Florianópolis, v. 14, n. 26 , jan./jun. 2013. p. 61 - 75

DOI: 10.5965/198472381426201361

http://dx.doi.org/10.5965/198472381426201361 


\title{
Contestation and resistance of children at the temporary shelter for homeless children of Santa Felicidade (Curitiba, 1947-1953)
}

\begin{abstract}
The present text identifies and analyzes the contestation and resistance of children in situation of poverty and abandonment at the Temporary Shelter for Homeless Children of Santa Felicidade within the period from 1947 to 1953 in the city of Curitiba. Thus, it approaches fragments of the lives of children who have built part of their life histories at that institution. The problem of the approach lies in inquiring the History and Historiography through the inquiry: What mechanisms of contestation and resistance may be identified in the behavior of children in situation of poverty and abandonment before the referrals of the institution? Given the analysis of the sources in the perspective of the Sociocultural History we may consider that the main mechanism of contestation by the children was manifested in the act of forging their own identity and the main mechanism of resistance by the children was observed in the act of escaping from the institution. With the act of forging their own identity and escaping, often with other children, the children appear as the subject of their own history.
\end{abstract}

Key-words: Child. Childhood. Contestation. Resistance. Temporary Shelter. 


\section{Introdução}

A identificação e análise dos atos de contestação e resistência de crianças em situação de pobreza e abandono, que se encontravam no Abrigo Provisório para Menores Abandonados de Santa Felicidade, ${ }^{1}$ no período de 1947 a 1953, na cidade de Curitiba, é o objetivo primordial desse texto. Dar conta desse objetivo é um duplo desafio, na medida em que, primeiro, como vêm assinalando diferentes autores ${ }^{2}$ que se embrenham pela História da Infância, as fontes de que os historiadores dispõem para produzir a escrita da história de crianças são, na maioria das vezes, documentos oficiais, governamentais e foram produzidas pelos e para adultos. Segundo, há poucas oportunidades de diálogo, na medida em que são ínfimas as pesquisas sobre a história da criança pobre e abandonada no Brasil. O que se encontra de mais contundente é a história das políticas de assistência à infância e a história das instituições de assistência à infância; contudo, a criança fica subsumida.

Os relatórios do Serviço de Assistência Social (SAS) do Abrigo Provisório para Menores Abandonados de Santa Felicidade enviados à Diretoria Geral de Educação eram realizados mensal e anualmente. Os relatórios mensais traziam informações gerais sobre números: matrículas; menores existentes no primeiro dia do mês; menores existentes no último dia do mês; menores reinternados durante o mês; encaminhados à assistência médica e à assistência dentária; internamentos procedentes da capital, procedentes do interior do estado e procedentes de outros estados; menores que frequentam as oficinas de costura, sapataria, alfaiataria, carpintaria e selaria; seções de horticultura, avicultura e

\footnotetext{
${ }^{1}$ Para conhecer outros aspectos que permeiam essa pesquisa, consultar a dissertação de mestrado de Silva (2009), intitulada: Abrigar o corpo, cuidar do espírito e educar para o trabalho: ações do Estado do Paraná à infância do "Abrigo Provisório para Menores Abandonados de Santa Felicidade" ao "Educandário Santa Felicidade" (Curitiba, 1947-1957).

2 Para Gouvea (2008, p. 106), a documentação produzida pelo adulto espelha as expectativas sociais dirigidas ao sujeito infantil mais do que suas formas de inserção num determinado momento histórico. Os discursos e práticas de socialização, ao se dirigir à criança, constroem um imaginário sobre a infância, produzindo modelos de gestos, hábitos, comportamentos que são material de socialização nos processos de formação de tais atores. A criança é também produto de tais práticas e discursos. Neste mesmo sentido, Kuhlmann Jr. e Fernandes (2004, p. 15-16) assinalam que, se a história da criança não é passível de ser narrada na primeira pessoa, se a criança não é nunca biógrafa de si própria, na medida em que não toma posse da sua história e não aparece como sujeito dela, sendo o adulto quem organiza e dimensiona a narrativa, talvez a forma mais direta de percepcionar a criança, individualmente ou em grupo, seja precisamente tentar captá-la com base nas significações atribuídas aos diversos discursos que tentam definir historicamente o que é ser criança.
} 
trabalhos manuais; atividades diversas e curso primário; desligamentos: transferidos para outros estabelecimentos, colocações na própria família e em outras famílias, fugas; visitas realizadas pela assistente social. As observações eram o único espaço para descrever ou reivindicar, entretanto pouco utilizado.

Os relatórios anuais eram mais sucintos, porém também apresentavam informações quantitativas (conforme pode ser visualizado na p. 7). Os modelos de relatórios privilegiaram informações quantitativas durante todo o período de 1947 a 1953. Há, nesse período, apenas três relatórios descritivos que diferem do modelo e narram informações detalhadas sobre a situação das crianças na instituição. O modelo de relatório era provavelmente o mesmo para todas as instituições mantidas pelo Estado, na medida em que o abrigo provisório não possuía oficinas, ainda que listadas em todos os relatórios.

As mensagens de governo trazem informações gerais sobre o estado do Paraná. $\mathrm{Na}$ parte sobre serviço social apresenta as instituições de assistência mantidas pelo estado, caracterizando-as brevemente. Já os relatórios da Secretaria de Estado dos Negócios do Trabalho e Assistência Social trazem informações mais detalhadas sobre como se desenvolve a assistência à infância na instituição. Normalmente, o secretário reitera as observações e reivindicações da instituição.

Os relatórios e mensagens de governo, utilizados para o presente trabalho, são as fontes que possibilitaram chegar aos fragmentos da vida das crianças que nessa instituição construiriam parte de suas trajetórias de vida. A problemática da abordagem reside em inquirir a história e a historiografia através da indagação: que mecanismos de contestação e resistência podem ser identificados nas atitudes das crianças em situação de pobreza e abandono frente aos encaminhamentos da instituição? Pela análise das fontes, na perspectiva da História Sociocultural, trilha-se um caminho que tenta visualizar uma criança que emerge como sujeito de sua própria história. 


\section{A identidade da criança: contesta-se em busca de um nome}

Quando a criança chegava ao "Abrigo Provisório para Menores Abandonados de Santa Felicidade", sua identidade já estaria previamente forjada, pois, no decorrer da história, a criança em situação de abandono já havia adquirido uma multiplicidade de identidades, passando a configurar-se como abandonada, delinqüente, desvalida, menor, deserdada da sorte, desamparada, infeliz, desprotegida" (CÂMARA, 2006).

Dessa forma, sua chegada à instituição, com exceção dos casos em que era levada pela própria família ou em situações em que era encontrada com documentação, cada uma delas optava por identificar-se corretamente, ou forjar uma identidade. Esse ato pode ser considerado como uma forma de contestação por parte da criança. Referindo-se ao ato de contestar, Bobbio (1992) elucida:

Enquanto contrária à aceitação, a contestação se refere, mais do que a um comportamento de ruptura, a uma atitude de crítica, que põe em questão a ordem constituída sem necessariamente pô-la em crise [...] expressa-se através de um discurso crítico, num protesto verbal, na enunciação de um slogan [...] é sempre apenas ideológica (p. 144-145).

O motivo que levaria uma criança a forjar sua própria identidade poderia ser justificado por vários motivos, tais como: realmente não sabia o seu nome completo (nesses casos ela inventava somente o sobrenome); não gostava de seu nome e fantasiava um nome que admirava; queria não ser encontrada pela família e propositadamente construía uma identidade fictícia; recusava-se a dar qualquer nome, preferindo não ser ninguém a ser ela mesma.

Todavia, independente da situação que levava a criança ou o adolescente a forjar sua identidade, alguns internos eram realmente quem eles queriam ser, mesmo que fossem posteriormente descobertos.

Alguns nomes dados pelas crianças chamam a atenção nos relatórios de 1947 a 1953: "Laudelino de Tal”, em 1949, foi aceito pelo Serviço de Assistência Social e consta na lista sem nenhuma observação; “Menor de nome ignorado”, em 1951, provavelmente a criança recusava-se a falar qualquer nome e o Serviço de Assistência Social não se 
empenhou em descobrir, pois vários meses se passaram e a criança continuava sendo chamada de "Menor de nome ignorado"; "Gregório", em 1951, ficou sem sobrenome durante toda sua estada na instituição; "Menor Mudo", também em 1951, passou a se chamar "Menor Mudo Moreno" e, posteriormente, "Mudo Moreno"; "Sezinho", em 1953, descobriu-se mais tarde que seu nome exato era “Celso Constantino”; “José Luiz Fonseca" teve seu nome retificado pela Assistente para "Roosewelt Resende"; "João de Souza" se chamava, na realidade, "João Batista de Oliveira".

Ao omitir ou forjar uma identidade, emerge uma questão: as crianças estariam utilizando, inconscientemente, um mecanismo de contestação para não serem descobertas? Essa constatação parece ser comum entre os pesquisadores da História da Infância:

Não saber o próprio nome, ou recusar-se a falar, ter o nome de seus pais acrescidos de "de tal", inventar um nome, também deve ter um sentido bastante singular para as famílias e as crianças. Os nomes foram importantes na história, nas relações de pertença em que se davam, tanto nas linhagens nobres, como nas famílias burguesas, pois a escolha de um determinado nome para os (as) filhos (as) significava uma determinada maneira de apresentá-lo à sociedade (VEIGA; FARIA FILHO, 1999, p. 83).

A lista de nomes das crianças que se encontravam no Abrigo Provisório permite observar que, entre os sobrenomes tipicamente brasileiros, destacavam-se os sobrenomes de origem polonesa ${ }^{3}$. Wachowicz (1981) destaca que os imigrantes poloneses que no Brasil chegaram foram, na maioria, depreciados na sociedade e se concentraram em atividades predominantemente agrícolas. Assim, no Paraná, o polonês emergente era reticente quanto à sua origem, pois "equivalia a admitir a procedência das mais baixas camadas sociais" (p. 13). Por essa razão, é possível que o número de crianças de origem polonesa no Abrigo Provisório fosse ainda maior, já que o uso de um

\footnotetext{
${ }^{3}$ Para melhor compreensão dos sobrenomes de origem polonesa, sugere-se consultar toda a obra de Ruy Christovam Wachowicz e Zdzislaw Malczewski (2000), na qual os autores, mesmo que eventualmente, fazem referência aos sobrenomes poloneses. Nessa obra é efetuado, especificamente, um estudo de sobrenomes poloneses; entretanto, os autores privilegiaram sobrenomes de pessoas de destaque social. Neste sentido, os sobrenomes elencados na obra não se encontravam nos nomes das crianças do Abrigo Provisório para Menores Abandonados de Santa Felicidade.
} 
sobrenome imaginário poderia ser uma alternativa de fuga de uma condição de camponês, polonês, imigrante, pobre e discriminado.

\section{Procura-se uma família e um lar}

Ao se referir à criança abandonada que chegava ao Abrigo Provisório, não há como ignorar os diferentes fatores de ordem familiar que contribuíram para que ela se encontrasse naquela situação. A família poderia tê-la abandonado recentemente pelas ruas da cidade, por não ter condições de sustentá-la; a família poderia tê-la abandonado na própria instituição, pelos mesmos motivos; a família poderia estar passando por dificuldades financeiras momentâneas e deixá-la na instituição, provisoriamente, acreditando que seria a melhor opção naquele momento; a criança poderia ter fugido de casa, para fugir da pobreza, buscando melhores condições de vida nas ruas da cidade; poderia ter fugido da família para se livrar de algum tipo de violência; ou, ainda, ela poderia ter se extraviado da família e não saber voltar para casa.

Evidencia-se, nos relatórios da instituição, que cerca de $30 \%$ das crianças que chegavam ao Abrigo, em 1949, voltavam para suas próprias famílias e, muitas vezes, eram enviadas de volta à família sem que esta tivesse recebido uma visita do SAS, pois o número de crianças entregues à própria família era maior que o número de visitas realizadas às suas famílias.

Emergem dessa situação duas hipóteses: o SAS não conseguia realizar as visitas e acabava sucumbindo ao desejo da família, que encontrava a criança na instituição e a levava de volta ao lar; o SAS não encontrava uma instituição para destinar a criança e, devido ao aumento do número de crianças na instituição a enviava de volta à família sem avaliar as condições em que ela viveria.

Em decorrência disso, grande parte dessas crianças acabava voltando para o “Abrigo Provisório para Menores de Santa Felicidade”. A partir dessa evidência, pode-se considerar a possibilidade da criança não só ser abandonada pela família, mas de ela própria abandonar sua família. Ela poderia sentir-se tão abandonada dentro de casa, 
vítima de trabalhos forçados, violência e/ou fome, que sua única opção seria fugir de uma situação indesejada.

E o fato de uma criança ser enviada para a casa da família não significava que esta não voltaria às ruas novamente. Exemplo é o de uma criança chamada Miroslau Fiatecoski. Ele foi internado em dezembro de 1947, desligado e enviado de volta para a casa de sua família em julho de 1948, vindo a ser reinternado em fevereiro de 1949 e transferido para o Centro de Formação Profissional para Menores de Campo Comprido em fevereiro de 1949 (PARANÁ, 1949b, s/p).

Nota-se, no relatório das atividades da Assistente Social do Abrigo Provisório para Menores de Santa Felicidade (Figura 1), durante o ano de 1949, que poucas crianças eram colocadas em outras famílias, assim como o número de famílias que aceitavam crianças também era ínfimo.

No “Abrigo Provisório", o SAS estudaria o caso de cada criança que se encontrava na instituição e, sob a anuência do Juizado de Menores, determinaria o seu destino: voltar para o meio familiar, ser colocada em outra família ou ir para uma escola profissional.

Voltar para o meio familiar seria uma alternativa se o SAS conseguisse contato com os familiares. Um dos fatores que dificultavam o contato era a falta de resposta de parte deles, como no caso em que a assistente social expõe:

Não foi possível fazermos maior número de visitas e colocações, por ser a maioria dos internados procedentes do interior, havendo grande dificuldade na parte referente às correspondências, que geralmente ficam sem resposta (PARANÁ, 1949b, s/p).

Sem conseguir contato com os familiares para avaliar a possibilidade de um possível retorno ao lar, restaria ao SAS colocar a criança em outra família ou encaminhá-la a uma escola profissional. Os dados referentes ao ano de 1949 evidenciam que havia um grande fluxo de crianças no abrigo e que algumas permaneciam por um longo período na provisoriedade. 


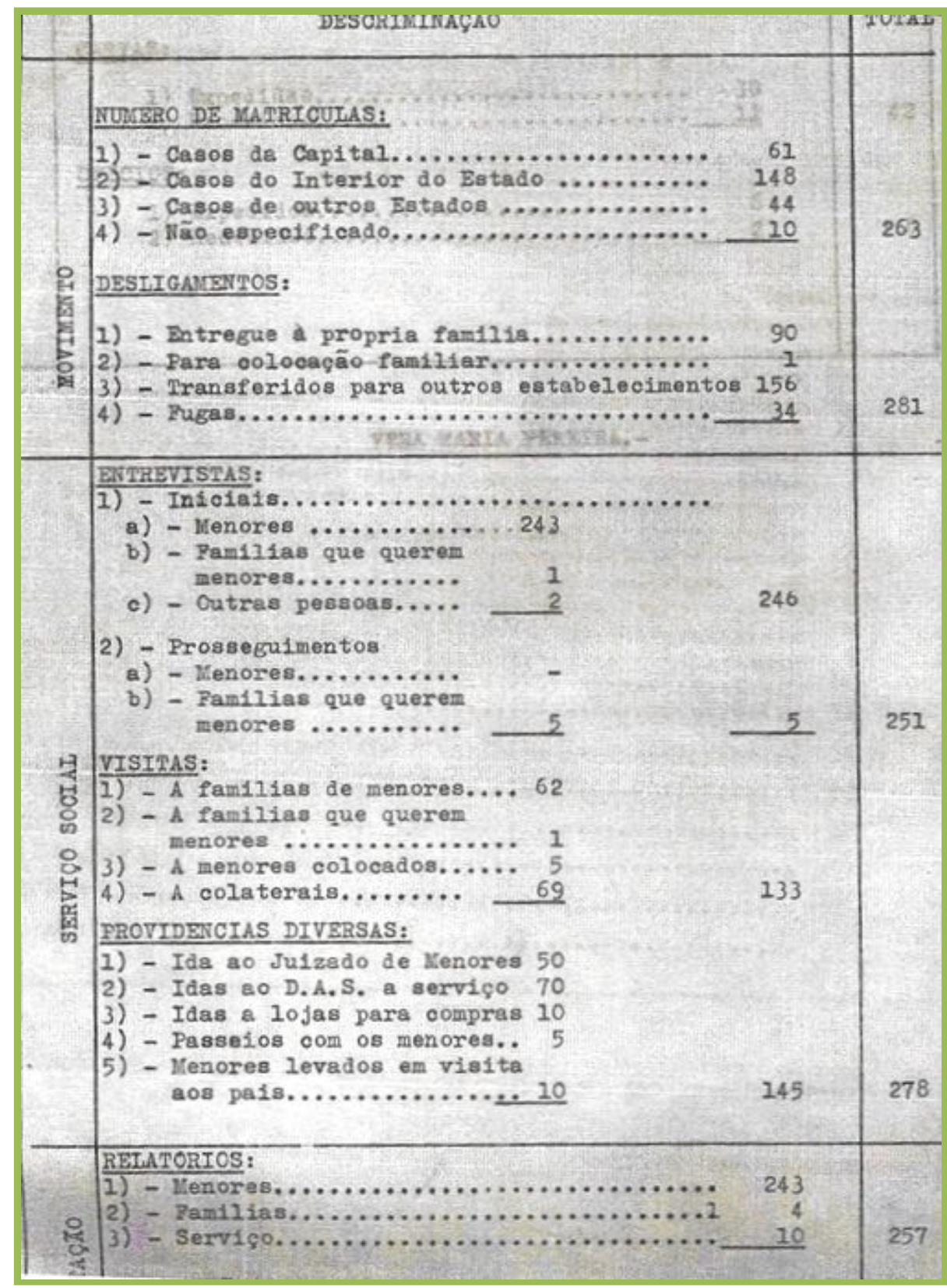

Figura 1 - Relatório de 1949

Fonte: Acervo do Arquivo Público do Paraná.

\section{Criança em fuga: resistência como resposta à provisoriedade}

O grande número de foragidos e os reinternamentos no Abrigo Provisório sinalizam que uma grande parcela das crianças resistia às medidas socioeducativas, médico-higiênicas e de preparação para o trabalho que entremeavam a sua infância. A fuga seria um mecanismo que evidencia a resistência da criança. Nessa direção, Bobbio (1993) afirma: 
Enquanto contrária à obediência, a resistência compreende todo o comportamento de ruptura contra a ordem constituída, que ponha em crise o sistema pelo simples fato de produzir-se, como ocorre num tumulto, num motim, numa rebelião, numa insurreição, até o caso limite da revolução; que ponha o sistema em crise, mas não necessariamente em questão. [...] culmina essencialmente num ato prático. [...] não necessariamente violenta, pode chegar até o uso da violência (p. 144).

Portanto, o número de fugas constaria nos relatórios do SAS e mostraria ao sistema a insatisfação das crianças. Entretanto, essas fugas eram encaradas pelo SAS com certa naturalidade. Argumentava-se que "se tratando de Abrigo Provisório, tipo aberto, recebendo menores de toda procedência, é natural que ocorram fugas, principalmente as iniciadas por menores habituados a fugir e que conseguem levar outros consigo" (PARANÁ, 1949b, s/p).

As crianças reinternadas poderiam ter fugido da própria instituição, da escola profissional, da recolocação na própria família, ou da destinação para uma nova família. Nesse sentido, Bernal (2004) salienta:

Se por um lado a disciplina e o trabalho eram os "remédios" das instituições do Serviço Social de Menores, as respostas dos jovens ao tratamento seriam as mais variadas formas de resistência, sendo a indisciplina e as fugas as principais formas explícitas de demonstrar as insatisfações e possíveis avisos de que eram contra ao que lhes estava sendo imposto (2004, p. 114).

A partir dos relatórios do SAS, é possível identificar a trajetória de vida dos internos da instituição persistentes em suas fugas. Vejamos alguns exemplos:

- Milton Benedito Bezerra: foi internado no Abrigo Provisório em novembro de 1947, desligado para casa em março de 1948, de onde fugiu. Posteriormente, foi reinternado em dezembro de 1948 e transferido para o Centro de Formação Profissional para Menores de Campo Comprido em fevereiro de 1949.

- Luiz Fernandes Guimarães: foi internado em outubro de 1948, desligado por fuga em janeiro de 1949, reinternado em agosto, desligado novamente por fuga em 23 de setembro e reinternado no dia 28 do mesmo mês. Foi 
transferido para o Centro Profissional para Menores de Campo Comprido no dia 29 de setembro do mesmo ano.

- Altair Soares: foi internado no dia 6 de março de 1949, evadiu-se no dia 10, foi reinternado e evadiu-se novamente no dia 14 , mas voltou no dia 15 . Foi transferido para a Secretaria da Agricultura no dia 19. Tudo isso aconteceu no mesmo mês, porém sua trajetória institucional não terminaria. Ele voltou à instituição em maio de 1949, foi transferido para o Centro Profissional para Menores de Campo Comprido em julho de 1949, de onde se evadiu mais uma vez, porém foi reinternado, outra vez, no “Abrigo Provisório para Menores Abandonados de Santa Felicidade", no dia 9 de julho de 1949. Para esse menino, após as inúmeras fugas, o Abrigo Provisório seria sua melhor opção de vida.

Se, para algumas crianças, o "Abrigo" era um local de idas e vindas, uma vez que elas reincidiam nas fugas, independente do local onde estivessem, para outras, possivelmente conformadas com o destino determinado pelo SAS, ou sem coragem suficiente para se aventurar em uma fuga, a provisoriedade poderia representar o melhor destino.

Foucault (1987) auxilia na compreensão dessa situação ao esclarecer:

A disciplina fabrica, assim corpos submissos e exercitados, corpos "dóceis". A disciplina aumenta as forças do corpo (em termos econômicos de utilidade) e diminui essas mesmas forças (em termos políticos de obediência). Em uma palavra: ela dissocia o poder do corpo; faz dele por um lado uma aptidão, uma "capacidade" que ela procura aumentar, e inverte, por outro lado, a energia, a potência que poderia resultar disso, e faz dela uma relação de sujeição estrita (p. 128).

No caso das crianças do abrigo provisório, a possível disciplina existente na instituição poderia resultar na contestação ou na resistência assinaladas por Bobbio ou na sujeição abalizada por Foucault. 
$\mathrm{Na}$ análise das relações de nomes de internos existentes no "Abrigo Provisório para Menores de Santa Felicidade", elaboradas mensalmente pelo SAS, pode-se constatar que para algumas crianças a instituição seria a única alternativa.

Nessa direção, Nelson José da Silva foi internado em fevereiro de 1948 e seu nome constaria em todas as relações dos relatórios até janeiro de 1951. Durante este período não constou evasão, transferência ou desligamento e, a partir de janeiro de 1951, seu nome desapareceu dos relatórios do SAS; simplesmente submeteu-se a todos os encaminhamentos a ele direcionados.

\section{Considerações Finais}

A contestação e a resistência da criança, representadas pelos atos de forjar a identidade e/ou fugir, bem como de levar outra criança consigo, parecem ser os momentos nos quais mais identificamos a infância da criança pobre e abandonada. Diante disso, consideram-se as ideias de Ferreira (2002):

Ao significar que as crianças não se 'limitam'a reproduzir o mundo dos 'grandes'à sua escala, mas 'pelo avesso' o reconstroem e ressignificam através de múltiplas e complexas interações com os pares, permite mostrá-las não só como autoras das suas próprias infâncias, mas também como atores sociais com interesses e modos de pensar, agir e sentir específicos e comuns, capazes de gerar relações e conteúdos de relação, sentido de segurança que estão na sua gênese como grupo social (p. 59).

A instituição, enquanto “Abrigo Provisório", apresentou como primordial preocupação a triagem e o abrigo do corpo da criança. A grande preocupação com sua higiene, boas maneiras, saúde e preparação para o trabalho teria a finalidade de deixá-la apta a ser um cidadão benéfico a si mesmo, à coletividade e, sobretudo, ao Estado. 


\section{Referências}

BERNAL, Elaine Marina Bueno. Arquivos do abandono: experiências de crianças e adolescentes internados em instituições do Serviço de Menores de São Paulo (1938-1960). São Paulo: Cortez, 2004.

BOBBIO, Norberto. A era dos direitos. Rio de Janeiro: Campus, 1992.

CÂMARA, Sônia. Por uma acção preventiva e curativa da infância pobre: os discursos jurídico-educativos no Brasil e em Portugal nas décadas de 1910-1920. In: FERNANDES, Rogério; LOPES, Alberto; FARIA FILHO, Luciano Mendes de (Org.). Para a compreensão histórica da infância. Lisboa: Campo das Letras, 2006.

. Sob a guarda da república: infância menorizada no Rio de Janeiro da década de 1920. 2006. 468 f. Tese (Doutorado) - Universidade de São Paulo. São Paulo.

FERREIRA, Manuela. Do "avesso" do brincar ou... as relações entre pares, as rotinas da cultura Infantil(is) instituinte das crianças no jardim-de-infância. In: Sarmento, Manuel Jacinto; CERISARA, Ana Beatriz. Crianças e Miúdos. Portugal: ASA, 2002.

FOUCAULT, Michel. Vigiar e punir: história da violência nas prisões. Petrópolis: Vozes, 1987.

GOUVEA, Maria Cristina Soares de. A escrita da história da infância. In: SARMENTO, Manuel Jacinto; GOUVEA, Maria Cristina Soares de (Org.). Estudos da Infância: educação e práticas sociais. Petrópolis: Vozes, 2008. p.97-118.

KUHLMANN JR., Moysés; FERNANDES, Rogério. Sobre a história da infância. In: FARIA FILHO, Luciano (Org.). A infância e sua educação. Belo Horizonte: Autêntica, 2004. p. 15-33.

SILVA. Joseane de Fátima Machado da. Abrigar o corpo, cuidar do espírito e educar para o trabalho: ações do Estado do Paraná à infância do "Abrigo Provisório para Menores Abandonados de Santa Felicidade" ao "Educandário Santa Felicidade" (Curitiba, 19471957). 2009. Dissertação (Mestrado em Educação). Universidade Federal do Paraná. Curitiba.

VEIGA, Cynthia Greive; FARIA FILHO, Luciano Mendes de. Infância no sótão. Belo Horizonte: Autêntica, 1999.

WACHOWICZ, Ruy Christovam; MALCZEWSKI, Zdnislaw. Perfis polônicos no Brasil. Curitiba: Vicentina, 2000. 
. O camponês polonês no Brasil. Curitiba, Fundação Cultural, Casa Romário Martins, 1981.

\section{Fontes \\ Acervo da Biblioteca Pública do Paraná}

PARANÁ, Governo. Mensagem apresentada à Assembléia Legislativa do Estado por ocasião da abertura da sessão legislativa de 1948 pelo Senhor Moisés Lupion, governador do Paraná. Curitiba, 1948a.

. Mensagem apresentada à Assembléia Legislativa do Estado por ocasião da abertura da sessão legislativa de 1949 pelo Senhor Moisés Lupion, governador do Paraná. Curitiba, 1949 .

Curitiba, 1950a.

. A concretização do Plano de Obras do Governador Moysés Lupion (1947-1950).

. Mensagem apresentada à Assembléia Legislativa do Estado por ocasião da abertura da sessão legislativa ordinária de 1950 pelo Senhor Moisés Lupion, governador do Paraná. Curitiba, 1950 b.

. Mensagem apresentada ao povo do Paraná pelo Senhor Moysés Lupion, governador do Estado, ao término de seu mandato. Curitiba, 1950c.

. Mensagem apresentada à Assembléia Legislativa do Estado por ocasião da abertura da $1^{\text {a }}$ sessão ordinária da $2^{\mathrm{a}}$ legislatura pelo Senhor Bento Munhoz da Rocha Neto, governador do Paraná. Curitiba, 1951a.

. Mensagem apresentada à Assembléia Legislativa do Estado por ocasião da abertura da $2^{\mathrm{a}}$ sessão ordinária da $2^{\mathrm{a}}$ legislatura pelo Senhor Bento Munhoz da Rocha Neto, governador do Paraná. Curitiba, $1952 a$.

- Mensagem apresentada à Assembléia Legislativa do Estado por ocasião da abertura da $3^{\text {a }}$ sessão ordinária da $2^{\text {a }}$ legislatura pelo Senhor Bento Munhoz da Rocha Neto, governador do Paraná. Curitiba, $1953 a$.

. Mensagem apresentada à Assembléia Legislativa do Estado por ocasião da abertura da sessão legislativa ordinária de 1960 pelo Senhor Moysés Lupion, governador do Paraná. Curitiba, 1960.

. Secretaria de Saúde e Assistência Social. Realizações do Departamento Estadual da $\overline{\text { Criança }}$ durante o governo de Moysés Lupion. Curitiba, $1951 b$. 


\section{Acervo do Arquivo Público do Paraná}

PARANÁ. Diretoria Geral da Educação. Relatório enviado pelo Departamento de Assistência Social, Curitiba, 1948b.

. Diretoria Geral da Educação. Relatório enviado pelo Departamento de Assistência Social, Curitiba, $1949 b$.

. Diretoria Geral da Educação. Relatório enviado pelo Departamento de Assistência Social, Curitiba, $1950 d$.

PARANÁ. Diretoria Geral da Educação. Relatório enviado pelo Departamento de Assistência Social, Curitiba, 1951C.

. Diretoria Geral da Educação. Relatório enviado pelo Departamento de Assistência Social, Curitiba, $1952 b$.

. Diretoria Geral da Educação. Relatório enviado pelo Departamento de Assistência Social, Curitiba, 1953 b.

. Diretoria Geral da Educação. Relatório enviado pelo Departamento de Assistência Social, 1954.

- Secretaria de Estado dos Negócios do Trabalho e Assistência Social. Relatório apresentado ao Exmo. Sr. Governador, pelo Sr. Secretário de Estado, Dr. Abilon de Souza Naves, Curitiba, $1951 \mathrm{~d}$.

Universidade do Estado de Santa Catarina - UDESC

Programa de Pós-Graduação em Educação - PPGE

Revista Linhas

Volume 14 - Número 26 - Ano 2013 revistalinhas@gmail.com

Recebido em: 19/11/2012

Aprovado em: 13/04/2013 